\title{
The Impact of Implementation of the Canadian Regulatory Requirements on the Quality of Natural Health Products: The Glucosamine Case
}

\author{
Ali Aghazadeh-Habashi ${ }^{1}$, John Duke ${ }^{2}$, Fakhreddin Jamali $^{1}$ \\ ${ }^{1}$ Faculty of Pharmacy and Pharmaceutical Sciences, and ${ }^{2}$ SLOWPOKE Reactor Facility, University of Alberta, Edmonton, \\ Alberta, Canada \\ Received, February 10, 2014; Revised, February 22, 2014; Accepted, February 23, 2014; Published, February 24, 2014
}

\begin{abstract}
Purpose. We investigated whether the recent implementation of the regulatory requirements for the entry to the Canadian market of natural products has resulted in improved quality of the available glucosamine products. Methods. Eleven available products, of which 8 had been tested in 2002 ( 7 had contained substantially lower than the label claim of the active ingredient), and a European pharmaceutical grade tablet were assayed for their glucosamine content. The potassium and sodium contents of the products were also tested. Results. Nine of the 11 Canadian products and the European tablet had more than $91 \%$ of the label claim of the active ingredient, hence, met the criterion. Two products contained 71 and $78 \%$ label claim. The electrolyte contents were very variable but constituted only a small fraction of the daily requirements. Conclusion. Most tested glucosamine products passed the Health Canada requirements. This improvement is likely due to the publicity regarding the low quality of the products in the past and also a result, at least in part, of the introduction of the new regulatory requirements. The sub-standard quality of a few tested products is still of concern.
\end{abstract}

This article is open to POST-PUBLICATION REVIEW. Registered readers (see "For Readers") may comment by clicking on ABSTRACT on the issue's contents page.

\section{INTRODUCTION}

The well-acknowledged sub-standard quality of natural products in terms of their active ingredient content is generally attributed to the lack of regulations in their production and marketing (1-3). In 2002 we reported that 12 out of 13 Canadian products of glucosamine had substantially less active ingredient than what was stated on their respective labels (1). This has been suggested to be, at least in part, responsible for the controversy in the effectiveness of glucosamine as an anti-inflammatory drug (2). This is important, not only in terms of the product standard and regulatory issues but also therapeutically as recent data suggest dose/plasma concentration-dependence for the beneficial effects of glucosamine (4). Only in a few regions, e.g., the European Union, but not in North America, is glucosamine regulated as a pharmaceutical product. Recently, Health Canada has implemented a set of regulatory guidances governing natural products (5). Our aim was to examine if the introduction of these guidances has resulted in an improvement of the quality of Canadian glucosamine products. Since, most solid dosage forms of glucosamine contain sodium or potassium chloride for their physical stability, we also determined their potassium and sodium contents to assess if they exceeded the recommended safety limits.

\section{MATERIAL AND METHODS}

Glucosamine $\mathrm{HCl}$, mannosamine $\mathrm{HCl}$, amantadine $\mathrm{HCl}$ (1-aminoadmantane $\mathrm{HCl}, \mathrm{ADAM}$ ) and 9fluorenylmethoxycarbonyl chloride (FMOC-CL) were purchased from Sigma-Aldrich Canada, LTD, (Oakville, ON, Canada), high performance liquid chromatography (HPLC) grade acetonitrile and water were obtained from Caledon Laboratories Ltd, (ON, Canada).

\section{Products}

We searched the market for available glucosamine products, particularly those that we had examined and reported on in 2002 (1). We succeeded in purchasing 11 products (Table 1) from pharmacies or health products stores with 8 of them being those examined previously.

Corresponding Author: F. Jamali, Faculty of Pharmacy and Pharmaceutical Sciences, University of Alberta, Edmonton, Alberta, Canada T6G 2E1; fjamali@ualberta.ca. 


\section{Sample preparation and glucosamine assay}

Glucosamine stock solution was prepared by dissolving $60 \mathrm{mg}$ glucosamine $\mathrm{HCl}$ in $100 \mathrm{~mL}$ water to yield a $0.5 \mathrm{mg} / \mathrm{mL}$ solution of glucosamine base.

The stock solution was further diluted with water to give standard solutions containing $0.78,1.56,3.12$, 6.25 , and $12.5 \mu \mathrm{g} / \mathrm{mL}$, respectively.

The worker was kept blinded to the identity of the products. A positive control (Rottapharm, Monza, Italy) and a placebo tablet were also tested. Tablets and capsules were tested for their glucosamine and electrolytes contents. Five units of each tablet product were weighed, placed in a mortar and ground to a fine powder. For capsules the entire contents of 5 units were used. Four portions each of approximately $10 \%$ of the total powder were accurately weighed. Three portions were used for glucosamine determination and one for the electrolytes measurement. For glucosamine assay, the powders were dissolved in $1 \mathrm{~L}$ of distilled water by vortex-mixing for $30 \mathrm{~min}$ and passed through paper filter. Glucosamine salts are highly soluble in water, hence, it was expected to be all in the clear solutions. For the liquid formulations, 2 $\mathrm{mL}$ of the products were used. The solutions were diluted with water to yield a concentration of $10 \mathrm{mg} / \mathrm{L}$ and assayed for glucosamine using HPLC according to a previously reported procedure (6). Briefly, a 0.1 $\mathrm{mL}$ aliquot of standard or sample solution was spiked with $50 \mu \mathrm{L}$ of $10 \mu \mathrm{g} / \mathrm{mL}$ internal standard (mannosamine $\mathrm{HCl}$ ) and $50 \mu \mathrm{L}$ of borate buffer $(\mathrm{pH}$ 8.5) added followed by addition of $50 \mu \mathrm{L}$ of a freshly prepared FMOC-CL solution. This was followed by 1 min vortex-mixing and incubation in a water bath at $30^{\circ} \mathrm{C}$ for $30 \mathrm{~min}$. Subsequently, $50 \mu \mathrm{L}$ of ADAM 50 $\mathrm{mg} / \mathrm{mL}$ in acetonitrile:water $(1: 1)$ was added to the test tubes to react with the excess derivatizing agent. The samples were then diluted with $1 \mathrm{~mL}$ acetonitrile:water $(1: 1)$ and $5 \mu \mathrm{L}$ injected into the HPLC. The inter-day / intra-day assay coefficient of variation of the assay and the percent error were both less than $10 \%$. All products were tested within their manufacturer's recommended expiry dates.

\section{Potassium and sodium assays}

Instrumental neutron activation analysis (INAA) was used to determine the potassium and sodium contents of the products under study. Powdered samples, each measuring $200 \mathrm{mg}$, were accurately weighed into $300 \mu \mathrm{L}$ polyethylene micro-centrifuge tubes, hermetically sealed, and irradiated consecutively in 2
Table 1. Specifications of the glucosamine products tested

\begin{tabular}{lllll}
\hline Product $^{\mathrm{a}}$ & $\begin{array}{l}\text { Cap, } \\
\text { Tab, } \\
\text { liquid }\end{array}$ & NPN & Lot \# & Powder \\
& \multicolumn{2}{l}{ mg/unit } \\
\hline Jamieson & $\mathrm{L}^{\mathrm{b}}$ & 80001853 & 2816931 & N/A \\
Webber & $\mathrm{T}^{\mathrm{c}}$ & 80008385 & 687258 & 1524 \\
Wampole & $\mathrm{C}$ & 80000078 & 06241 & 741 \\
Jamieson & $\mathrm{C}$ & 80000370 & 2771095 & 744 \\
Botanical & $\mathrm{L}^{\mathrm{b}}$ & 80002343 & 350070 & $\mathrm{~N} / \mathrm{A}$ \\
Webber & $\mathrm{C}$ & 80000082 & 688270 & 712 \\
Webber & $\mathrm{C}$ & 80001560 & 696464 & 1028 \\
Natural & $\mathrm{C}$ & 80000122 & 680505 & 688 \\
Organika & $\mathrm{C}$ & 80000168 & 048602 & 707 \\
Quest & $\mathrm{T}$ & 80000518 & 11898 & 2265 \\
Prairie & $\mathrm{C}$ & 80009273 & 1831000 & 690 \\
& & & & \\
Rottapharm & $\mathrm{T}$ & $\mathrm{N} / \mathrm{A}^{\mathrm{d}}$ & 24080004 & 597 \\
\hline
\end{tabular}

a Jamieson Laboratories Ltd, Windsor ON; Webber Naturals, Coquitlam BC; Wampole INC, Boucherville PQ; Botanical, Burnaby, BC; Natural Factors, Coquitlam BC; Organika Health Product INC, Richmond, BC; Quest Purity Life Health Product, Acton ON; Prairie Naturals, Coquitlam BC; Rottapharm, Monza Italy. ; ${ }^{\mathrm{b}}$ Liquids, hydrocloride salt; ${ }^{\mathrm{c}}$ The only product that contained both the sulfate and hydrochloride salts as all other capsules (Cap) and tablets (Tab) contained sulfate only; ${ }^{\mathrm{d}} \mathrm{N} / \mathrm{A}$, Not applicable, a European product; NPN, Natural Product.

batches, together with standards, in the University of Alberta SLOWPOKE nuclear reactor for $360 \mathrm{~s}$ at a nominal thermal neutron flux of $3.5 \times 10^{11} \mathrm{n} \mathrm{cm}^{-2} \mathrm{~s}^{-1}$. Following a decay period of $\geq 17 \mathrm{~h}$ the irradiated samples were individually counted for $360 \mathrm{~s}$ on the end cap of a $40 \%$ relative efficiency ORTEC hyperpure Ge detector (Profile GEM-FX8530, FWHM of $1.76 \mathrm{keV}$ for the $1332.5 \mathrm{keV}$ full energy peak of ${ }^{60} \mathrm{Co}$ ) housed in a $10 \mathrm{~cm} \mathrm{~Pb}$ cave. The Ge detector was connected to an ORTEC DSPEC Pro digital spectrometer and measurements were performed in zero dead time counting mode. Elemental determinations were performed by the semi-absolute method of neutron activation analysis (7). $\mathrm{K}$ was determined via the $1524.7 \mathrm{keV}$ gamma-ray emission of ${ }^{42} \mathrm{~K}\left(\mathrm{~T}^{1} / 2,12.4 \mathrm{~h}\right)$ produced via the neutron reaction ${ }^{41} \mathrm{~K}(\mathrm{n}, \gamma)^{42} \mathrm{~K}$ whereas sodium was quantified 
Table 2. Glucosamine (GIcN) content of products tested in 2013 vs those reported in 2002, potassium and sodium contents in $1500 \mathrm{mg}$ recommended daily doses, and the product total powder mass.

\begin{tabular}{llllll}
\hline \multirow{2}{*}{ Product $^{\mathrm{a}}$} & \multirow{2}{*}{$\begin{array}{l}\text { Labeled } \\
\end{array}$} & GlcN, mg & \multicolumn{2}{c}{$\begin{array}{c}\text { \% of the labeled } \\
\text { GlcN content }\end{array}$} & \multicolumn{2}{c}{$\mathrm{K}$} & $\mathrm{Na}$ \\
& & $\mathbf{2 0 0 2}$ & $\mathbf{2 0 1 3}$ & $\mathrm{mg} / 1500 \mathrm{mg}^{\mathrm{c}}$ \\
\hline Jamieson & $500 / 5 \mathrm{~mL}$ & ND & $\mathbf{1 1 1}(\mathbf{2 . 2})$ & $\mathrm{ND}$ & $\mathrm{ND}$ \\
Webber & 500 & $\mathbf{1 0 8}$ & $\mathbf{1 0 5}(\mathbf{2 . 0})$ & 361.7 & 104.3 \\
Wampole & 500 & $\mathbf{5 0}$ & $\mathbf{1 0 4}(\mathbf{7 . 9})$ & 335.9 & 0.49 \\
Jamieson & 500 & $\mathbf{5 5}$ & $\mathbf{1 0 4}(\mathbf{7 . 2})$ & 330.3 & 0.56 \\
Botanical & $500 / 7.5 \mathrm{~mL}$ & $\mathbf{N D}$ & $\mathbf{1 0 4}(\mathbf{2 . 9})$ & $\mathrm{ND}$ & $\mathrm{ND}$ \\
Webber & 500 & $\mathbf{6 5}$ & $\mathbf{1 0 1}(\mathbf{2 . 4})$ & 316.0 & 4.18 \\
Webber & 750 & $\mathbf{N D}$ & $\mathbf{1 0 1}(\mathbf{2 . 1})$ & 369.9 & 0.49 \\
Natural & 500 & $\mathbf{6 0}$ & $\mathbf{9 4}(\mathbf{2 . 2})$ & 326.2 & 0.29 \\
Organika & 500 & $\mathbf{6 6}$ & $\mathbf{9 1}(\mathbf{2 . 6})$ & 324.6 & 0.04 \\
Quest Purity & 1500 & $\mathbf{4 2}$ & $\mathbf{7 8}(\mathbf{2 . 2})$ & 251.5 & 2.04 \\
Prairie & 500 & $\mathbf{5 5}$ & $\mathbf{7 1}(\mathbf{1 . 0})$ & 256.5 & 0.05 \\
& & & & & \\
Rottapharm & 250 & ND & $\mathbf{9 4}(\mathbf{1 . 1})$ & $\leq 17.9$ & 174.8 \\
\hline
\end{tabular}

${ }^{a}$ Product's sponsor are listed in Table 1; ${ }^{b}$ Data presented as mean (SD), $\mathrm{n}=3 /$ product; ${ }^{\mathrm{c}} 1500 \mathrm{mg}$ is the common daily dose. ND, not determined.

using the $1368.6 \mathrm{keV}$ gamma-ray emission of ${ }^{24} \mathrm{Na}$ $(\mathrm{T} 1 / 2,15.0 \mathrm{~h})$ produced via the neutron reaction ${ }^{23} \mathrm{Na}(\mathrm{n}, \gamma){ }^{24} \mathrm{Na}$. The $\mathrm{K}$ and $\mathrm{Na}$ comparator standards were prepared from Aldrich Chemical Co., gold label potassium- and sodium-carbonate, both of $99.999 \%$ purity, that had been dried for over 3 hours at $105 \pm 5^{\circ} \mathrm{C}$. Sodium was quantified in all the samples analyzed. However, the European product contained a high level of sodium and no detectable level of potassium. For that sample the $\mathrm{K}$ detection limit was calculated following Currie (8).

\section{RESULTS AND DISCUSSION}

The pharmaceutical grade product available in the European market contained $94 \% \pm 1.1$ of the label claim amount of glucosamine which was within the acceptable range (Table 2). No glucosamine was detected in the placebo.
Since 2012 all natural health products must be licensed before they can be sold in Canada. To become licensed, applicants must provide Health Canada detailed information on the product, including its medicinal ingredients, source, dose, potency, non-medicinal ingredients and recommended use(s) (5).

As depicted in Tables 1 and 2, we were able to acquire 8 products whose glucosamine content had been previously reported (1). In addition, we tested two liquid formulations and one capsule as well as a European pharmaceutical grade product that had not been included in our 2002 report. Overall, the glucosamine content of the tested products ranged from 71 to $110 \%$ of their respective label claim. Eight of the 11 tested Canadian products contained more than $91 \%$ of what was claimed on the label. The three new Canadian products contained 101$110 \%$ of the label claim. 
According to the USP a typical pharmaceutical formulation should contain from 90 to $110 \%$ of the labeled amount (9). Glucosamine is not considered as a pharmaceutical product in Canada and the USA. However, it is listed in the USP and its tablets or capsules are expected to contain $90-110 \%$ of claimed amount (9). The Health Canada regulatory requirement states that "The tolerance limits for the quantity of medicinal ingredients should conform to the relevant pharmacopoeial standard or in its absence to $80 \%$ to $120 \%$ of the label amount" (5). Assuming the USP as a "relevant pharmacopoeia", glucosamine products should contain $90-110 \%$ of the label claim. Accordingly, 9 of the 11 tested products contain acceptable pharmaceutical potencies. In contrast, in 2002, 7 of the 8 of the tested products were found to contain only $42-65 \%$ of the label claim (1).

The substantial improvement in the quality of the examined products is encouraging. It is, however, unclear whether the observed improvement is due to the implementation of the regulations (5) or the awareness that was brought about through the literature (1-3).

It is, however, still alarming that two of the previously tested products that had 42 and $55 \%$ of the label claim, albeit improved, have lower than the acceptable 90\% limit (78 and 71\%, respectively). The sub-standard quality of the products observed in this study, although just a few, may be attributed to the soft nature of the regulatory requirements and/or the lack of an obligation to conform for already marketed products. The Health Canada Guidance states that "Because Health Canada has not yet evaluated all natural health products currently on the market, products with exemption numbers can also legally be sold in Canada. The exemption number will be listed on the product label in the form ENXXXXXX" (5)". We found only the natural health number (NPN) on all of the Canadian products (Table 1).

The observed sub-standard quality appears to be not limited to the available natural products. Serious concerns have been raised regarding the quality of the pharmaceutical products compounded in pharmacies across the USA in 2001 and again in 2006 (10). In 2006, the US Food and Drug Administration (FDA) conducted a study on the quality of the formulations compounded in pharmacies. They collected 125 active pharmaceutical ingredients used for compounding and 73 finished formulations prepared onsite. The samples comprised female hormone, inhalation and local anesthetic products. For various reasons only 36 samples were analyzed for their potency. Nevertheless, 12 of the 36 samples, i.e., $33 \%$ failed to meet the required criteria set by the agency due to both sub- or super-potencies ranging from as low as $67.5 \%$ to as high an $268 \%$ of the labeled claim. To the best of our knowledge, such data are not available for products compounded in other countries but it is reasonable to predict similar conditions to those reported in the USA. Similar to the natural products, on-site compounded formulations are subject to very few, if any, regulations. Hence, the quality of both natural products and pharmacy compounded formulations is likely more dependent on the skills and standards of the makers rather than the regulatory guidelines.

The observation that the tested liquid formulations contain glucosamine at the pharmaceutical grade level is therapeutically important. Glucosamine tablets are excessively bulky - up to $2.3 \mathrm{~g} /$ tablet (Table 1) -, making them difficult to swallow, particularly so by elderly subjects that constitute a large portion of patients in need of the compound. The large size of the products contributes, at least in part, to the suggestion of underdosing of glucosamine (2). Glucosamine salts are highly water soluble, hence, their liquid formulations can readily be prepared. The availability of these readily swallowable liquid formulations may improve patient compliance.

Depending on the information source, the daily requirement of sodium ranges from 1.3 to $1.5 \mathrm{~g}$ (11). In general, the average North American adult consumes much more that than the required sodium amount. For potassium the daily requirement is approximately 4.5-4.7 $\mathrm{g}$ (9). The sodium and potassium contents of the tested products, adjusted for the common daily dosage of $1500 \mathrm{mg} / \mathrm{kg}$, was very variable for both sodium $(0.05-104.3 \mathrm{mg})$ and potassium $(\leq 17.9-361.7 \mathrm{mg})$ but were not at levels to raise concern. 
In conclusion, there is a substantial improvement in the quality of the present glucosamine products available in Canada as compared to those tested in 2002. This, although cannot be unequivocally claimed, may be attributed to the implementation of the new regulatory requirements governing natural products. Nevertheless, one can still find substandard products due, perhaps, to the less stringent nature of the regulations governing natural products as compared with those in place for pharmaceutical products and the overwhelming availability of the products introduced to the market before the new guidance.

Conflict of interest. None of the authors have any conflict of interest regarding the material presented in this paper.

\section{REFERENCES}

1. Russell AS, Aghazadeh-Habashi A, Jamali F. Active ingredient consistency of commercially available glucosamine sulfate products. $\mathbf{J}$ Rheumatol. 2002;29(11):2407-9.

2. Aghazadeh-Habashi A, Jamali F. The glucosamine controversy; a pharmacokinetic issue. J Pharm Pharm Sci. 2011;14(2):264-73.

3. Oke S, Aghazadeh-habashi A, Weese JS, Jamali F. Evaluation of glucosamine levels in commercial equine oral supplements for joints EquineVet J. 2006;38 (1):93-5.
4. Aghazadeh-Habashi A, Kohan MH, Asghar W, Jamali F. Glucosamine Dose/Concentration- Effect Correlation in the Rat with Adjuvant Arthritis. J Pharm Sci. 2014;103 (2): 760-7.

5. http://www.hc-sc.gc.ca/dhp-

$\mathrm{mps} /$ consultation/natur/consult_quality-qualiteeng.php.

6. Ibrahim A, Jamali F. Improved sensitive high performance liquid chromatography assay for glucosamine in human and rat biological samples with fluorescence detec-tion. J Pharm Pharm Sci. 2010;13(2):128-35.

7. Bergerioux, C., Kennedy, G. and Zikovosky, L. Use of the semi-absolute method in neutron activation analysis. J Radioanal Chem. 1979:50:229-34.

8. Currie, LA. Limits for quantitative detection and qualitative determination -application to radiochemistry. Anal.Chem,1968:40:586-93.

9. http://www.uspbpep.com/usp32/pub/data/v322 70/usp32nf27s0_m35205.

10. http://www.fda.gov/drugs/guidancecompliance regulatoryinformation/pharmacycompounding/ ucm204237.htm.

11. http://www.hc-sc.gc.ca/fnan/nutrition/reference/table/ref_elements_tbleng.php). 